that their oratory arises form their own original deliberations. The book is also too costly to circulate widely among concerned members of the public who need the information to allow them to make correct decisions on environmental problems. Also, though well written, the style is of the good scientific paper, which may present difficulties to those used to lighter literature.

So, although Dr Martin Holdgate's $A$ Perspective of Environmental Pollution is a fine book, valuable to the élite, it may not reach the mass audience envisaged by the publisher who wanted me to write Pollution in Perspective. So I fear that $\mathrm{Dr}$ Holdgate may not have let me off the hook, and that I may still have to write my own book. If I do, I, like all future writers on this topic, will have to thank him for marshalling so much information so admirably, and for reducing our work so considerably.

Kenneth Mellanby is Editor of the international journal Environmental Pollution.

\section{Pragmatic humanism}

\section{Stephen H. Schneider}

The Climate Mandate. By W. Roberts and H. Lansford, Pp. 197. (Freeman: San Francisco and Reading, 1979.) Hardback $£ 6.70$; paperback $£ 3.30$.

IN the past five years at least twice this number of popular books on climate has crossed my desk. Some promise ice (for example, The Cooling), others fire (for example, Hothouse Earth) and one even has the title Ice or Fire? Among these offerings one of the most recent, The Climate Mandate, is one of the best. Its authors are Walter Orr Roberts, former Director of the National Center for Atmospheric Research (NCAR) and Henry Lansford, a science writer and former Informaion Officer at NCAR. Dr Roberts is presently Director of the Program in Food, Climate and the World's Future of the Aspen Institute for Humanistic Studies. His concerns with humanity are well reflected in The Climate Mandate.

The team of a scientist/humanist and a science-writer has resulted in a very readable (and mercifully short - only 197 pages) selection of topics related to climate and climatic change. We are spared the uncaveated railings and pet theories of some climatic prognosticators that climatic doom is nigh as well as the bland assurance of some ostrich-like professional meteorologists that there is no climate problem worthy of public note, let alone a dozen books.

Of course, in 197 pages one cannot fully lay out the range and depth of all phases of the climate problem. The Climate Mandate will thus likely be only a partial help to those looking for a non-specialist textbook on climatic change to supplement, say, a beginning level college course in geography. On the other hand, it is much better than most of its competitors in confronting directly the place of climate and climatic variability in the world food picture. In fact, the book is organised to build up to the last chapter ("Defining the Problem - Malthusian Pessimists, Social Idealists, and Technological Optimists") in which the authors offer scenarios for world development within the demanding constraints of population growth, environmental stress, ideological differences, economic inequities and, of course, fluctuating climate. The scenarios comprise "the climate mandate".

To back up their solutions to the world predicament, there are chapters which review briefly climate history; the physical factors influencing climate; the climate theories of various scientists; the difficulties of climate forecasting; the respective roles of climate; technologies and infrastructure in crop productivity; and a cautious description of some weather modification operations in the US. If one extrapolates slightly from their carefully hedged remarks on weather modification, they seem to suggest that more dollars have flowed from granting agencies to weather modifiers than from seeded clouds to water users. They caution that such technological fixes are not panaceas, an apt thought in which to transition to the final chapter, where the food/population/energy/environment/climate problem (that is, the human predicament) is addressed.

The human predicament had been addressed often in the two hundred years since Malthus, and Roberts and Lansford bring it up to date with an overview of three modern contrasting views. First, there are the "Malthusian pessimists", personified by ecologist Garrett Hardin, who counsel "lifeboat ethics", whereby rich countries like the US are advised to abandon hope of feeding chronically poor countries with high population growth rates. The "technological optimists", on the other hand, believe that modern energy and capital-intensive farming can easily accommodate the foreseeable growth of world population - if only Third World governments would provide markets for farmers to sell their produce and incentives for corporations to transfer their technologies. Finally there are the "social idealists", who fear that transfer to the poor of modern large-scale technologies is another form of imperialism, as it makes the developing countries dependent on products developed and produced abroad. They counsel the overthrow of the "elites" who dominate Third World governments and the establishment of locally selfreliant, labour-intensive production systems.

Roberts and Lansford believe, as do I, that it is simplistic to view the human predicament simply as a problem of monolithic cause ("the danger lies in the conviction that a single aspect of the problem is so overriding that attempts to deal with any others are simply a waste of time and money"'). They propose, instead, an approach they call "pragmatic humanism", in which we are to accept the "premise that many human lives can be saved and much misery avoided by a diversity of efforts". Technology or the Green Revolution are legitimate tools in this "whole-system approach", but their applications must meet local needs. The authors then offer "scenarios" which comprise "the climate mandate". The first element is to establish a "world food emergency reserve" and distribution system to mitigate the effects of local climatic variability. (This reviewer could hardly disagree without revoking his own writings.) Next is the need to develop agricultural self-reliance in developing nations - with US and USSR joint-help. The key to success is flexibility and cooperation on all sides. Specific examples of how to bring this about, however, are few. According to their scenarios the Earth could "have the ability to produce adequate food for a doubled or tripled world population", but they admit (and unfortunately this is the only reference to this crucial issue) that "the ecological implications have not been examined in any comprehensive way'.

The authors conclude optimistically, despite the litany of obstacles they properly point out, that "if we heed the climate mandate, and if we accept the fact that the Earth's people are bound together by mutual needs and expectations that must transcend our rivalries and contests, humanity should be able not only to survive but to prevail over the hunger and starvation that have threatened so many people for so many centuries."'.

The Climate Mandate is a compassionate book; it reflects the authors' own humanity. Its hopes and sentiments are appealing. But if past experiences with global cooperation remain our only reference, I would continue to rate the prospects as "technologically optimistic, but politically bleak"'

Stephen H. Schneider is a climatologist at the National Center for Atmospheric Research, Boulder, Colorado, and Editor of the journal Climate Change. 